Bulletin of the Transilvania University of Braşov - Special Issue

Series VII: Social Sciences • Law • Vol. 13(62) No. 1 - 2020

https://doi.org/10.31926/but.ssl.2020.13.62.3.5

\title{
THE EFFECTS OF DANCING ON YOUNG PEOPLE WITH DOWN'S SYNDROME
}

\author{
Raluca CRIŞAN ${ }^{1}$
}

\begin{abstract}
Dance and movement therapy is about the creative use of movement and dancing in a therapeutic alliance. The present study analysis semi-structured interviews from people connected to young people with Down's syndrome. Our subjects practiced dances like ballet, zumba, vals, tango and also therapeutic movement. Some of them proved their skills in events specially organized for people with disabilities, but also in inclusive events, where they danced together with professional dancers, in Romania, Republic of Moldavia and Italy. The effects of dancing include increased selfesteem, relaxation, social inclusion, improved learning skills; they also developed social skills, because they met a lot of people in different social contexts.
\end{abstract}

Key words: dance, therapy, Down's syndrome, interviews.

\section{Introduction}

As it has been discovered and talked about for a few years now, practicing dance has multiple benefits because "the benefits of dance or creative movement may be experienced even without the aid of a licensed dance therapist" (Leseho \& Maxwell, 2010 , p. 18). Dancing helps with communication skills, reduces social anxiety, improves self-esteem, confidence and the quality of life.

\subsection{Dance and movement therapy}

"Dance Movement Therapy is the use of expressive movement and dance as a vehicle through which an individual can engage in the process of personal integration and growth. It is founded on the principle that there is a relationship between motion and emotion and that by exploring a more varied vocabulary of movement people experience the possibility of becoming more securely balanced yet increasingly spontaneous and adaptable. Through movement and dance each person's inner world becomes more tangible, individuals share much of their personal symbolism and in

${ }^{1}$ CJRAE Cluj, crisan.raluca@gmail.com. 
dancing together relationships become visible. The dance movement therapist creates a holding environment in which such feelings can be safely expressed, acknowledged and communicated" (Payne, 2004, p. 4). This definition is cited by Helen Payne from the ADMT (Association of Dance and Movement Therapy) and Standing Committee for Arts in Great Britain.

There are two principles that are involved in therapeutic dance: the body and the mind interact in a way that will change the total functioning; the improvisation through movement permits the client to experience new ways of being. Dance offers the body an occasion to express itself and it acts as a connection between the mind, body and spirit. Dance offers an opportunity for healing and growth (Leseho \& Maxwell, 2010).

\subsection{Down's syndrome}

Down's Syndrome is a genetic disorder associated with developmental delays - in motor skills, intellectual skills, speaking problems; it raises problems for posture and mobility (Albin, 2016). It is the most frequent genetic condition that causes intellectual limitations, it is associated with very important limitations in thinking and physical functioning (de Farias \& Teixeira-Machado, 2016)

\section{Literature and Results of other Studies}

The general idea of other studies is that dancing is an educational opportunity that involves different aspects in order to develop the construction of learning and collaborates to the psychomotor, social and cultural development. The benefits of dancing are on a large scale: they go from enhancing the body - mind connection to the improvement of development, health and cognitive skills. One case study (Reinders, Bryden \& Fletcher, 2015) communicated the opinion of the respondents: dance has social, physical and psychological benefits for a young man with Down's syndrome (he was 21 at the time of the study). Dance classes offered him the occasion to enlarge his social circle, made appeal to his cognitive abilities, and made him become active from a physical point of view.

Dance can be a hobby or it can be practiced in a special form as therapy. Dancing has beneficial effects in any 'shape', form, location - it can be done alone at home, with a group, private lessons or as therapy. As one of many studies relates, dance effects in the general population are about empowerment, transformation and healing, connection to spirit (Leseho \& Maxwell, 2010).

The relationship between body and mind is a premise for people who seek movement approaches for a holistic experience of mental, emotional and physical well-being and personal development (Dulicai \& Schelly Hill, 2007 cited in Leseho \& Maxwell, 2010).

Leseho \& Maxwell (2010) describe a research project focused on the relationship between dance / creative movement and healing, growth and survival. Emotion is expressed through dance, and this expression is organic, natural and immediate. If the emotion changes even a little bit the body moves in a different way in order to illustrate the changes of intensity or lightness. The origin of dance/movement as a 
psychotherapeutic technique comes from Carl Gustav Jung, with his concept of active imagination. Jung valued highly the therapeutic effects of artistic experience. Somatic psychology is a large umbrella for different approaches but the common element is the idea that the body reflects the mind and the mind reflects the body. This relationship is so powerful that if we work with one, the other is influenced. Dance is healing and transformative, it allows the communication of feelings without words. Some emotions are stored in the body and dance or creative movement offers a way to release them. The body speaks through dance. Dancing offers a connection between the mind, body and spirit. The study is based on stories about healing and growth through dance and creative movement. The results highlighted three major themes: empowerment, the first, transformation and healing, the second, and connection to spirit as the third. For each theme there are a number of subthemes. For empowerment the sub themes are: appreciation and respect for their bodies, reclaiming their bodies, embracing their femininity and a sense of freedom. The visible signs of transformation and healing are letting go, expressing emotions, changes in emotional state. coping with stress and sense of presence or grounding. The theme of connection to spirit has also a few sub themes: experiencing the sacred within, one's essence or core, connection to The Divine, wholeness.

Dance effects on people with Down's syndrome are also beneficial. Physical benefits include increased coordination, strength, endurance and motor abilities, flexibility; dance fosters communication skills, reduces social anxiety (Reinders, Bryden \& Fletcher, 2015). Another study affirms that introducing dance lessons is crucial to their development - it results in decreased anxiety in social settings, improved quality of life, increased independence and confidence and improved communication skills (Albin, 2016). Psychological benefits are about increased self - esteem, confidence, body awareness and capacity to remember dance moves (Reinders, Bryden \& Fletcher, 2015).

Benefits of dance and movement for people with Down's syndrome range from strengthening the mind - body connection to the improvement of development, health and cognitive skills (Albin, 2016). There is a very powerful trend towards sedentary life for people with Down's syndrome and movement based programs could alter this trend (Albin, 2016).

The most visible transformation as a result of dancing involves educational, emotional and social development. Dance is "a fundamental strategy and agent facilitator of functional independence" (de Farias \& Teixeira-Machado, 2016, p. 22).

"The established interaction between persons with Down's syndrome through dance provided the inclusion of social being in search of their inherent human skills, because this art is not just a set of elaborate steps to perform an action, dance allows the comprehension, learning and performance the body as a whole and this fact enables the communication, education and interaction between Down syndrome and all the kinds of people in society" (ibidem). 


\section{Methodology}

I asked the respondents to tell me their story about dancing and I prepared a few questions in case the story needed an impulse to continue. My questions were divided into a few categories: The effects of dancing: "tell me a story about the way dancing helps people with Down's syndrome to feel and develop"; How long have they been dancing, a timeline; What changes did you notice; What they like, what they don't like; What is hard, difficult, what they avoid; What are the feelings associated with dancing; One subject was about the events they participated in. I gathered stories (semi structured interviews): 3 parents, one volunteer involved in dance classes at a day center, one-day center coordinator, and one activitiy coordinator - for music therapy, theater and dance.

The respondents were involved in the activities of three day centers visited by young people and adults with Down's syndrome. The first day center had different dance teachers corresponding to various dance activities: waltz, Zumba, ballet, tango. This NGO included in its activities the organization of inclusive events like artistic competitions and parties. Their beneficiaries also participated in events organized by other entities and this resulted in increased confidence for them and joy for the parents. One of the beneficiaries obtained a Zumba teacher diploma. The second NGO collaborated with different dance teachers, and this resulted in learning different dancing styles, it had one location for dancing (dancing studio) and fixed timetables (dance classes are always on Monday at 4 p.m.). They also have a professional coordinator for medical gymnastics, in a separate class. The third day center had one coordinator of activities, also with experience in music therapy, actually music therapy preceded dancing activities, and it was taught in a professional manner by specialized teachers coming from abroad.

\section{Results}

As it is stated in the stories, dancing is beneficial for social skills, self - esteem, creativity, communication skills, learning skills, self - imposed discipline, relaxation. Two of the respondents talked about going beyond personal limits: before he or she did it, I didn't think that she or he could do it (dancing in a certain way).

The respondents who witnessed the beginnings of dancing activities shared the same observation: it was hard for the young people with Down's syndrome to get involved in dancing activities. Some of them were very shy, others were scared, and it took them a few classes (hours) to dare to participate in dance classes. Also, the learning process was very difficult in the beginning: it was very hard to learn the steps, it took a lot of work, repetitions, patience from all people involved in the process. The lack of physical activities was very obvious. It was a process that started with the beneficiaries being shy, withdrawn or scared and it took them to a point where they were open to communication, relaxed in social situations and eager to express themselves.

As it is most probably normal, all the interviews revealed a very special relationship to music. It is important to be reminded that one of the NGOs started music therapy 
before being involved in dancing activities. Two of the mothers witnessed the same situation with their children: during music shows they were so impressed it made them cry. One young woman with DS walked by a public place with music playing, it was a festival, and she started dancing in a spontaneous manner. As her mother told the story, the people around her started paying attention and encouraging her.

The volunteer involved in dancing activities talked about the playlist: it was a process to agree on it, it contained more than one music genre (salsa, tango and modern music). Other stories related to music refer to the differences: some of them like classical music, some of them like folk music, and these differences give rise to conflicts. All of the parents said that their children listen and dance to music at home and this makes them feel better.

As stated by the parents, volunteers and activity coordinators, the participation in events resulted in increased self - esteem and empowerment. Dancing offers multiple opportunities for emotional expression. There are many ways in which dancing activities resulted in increased self - esteem. One way to get it was for each of the beneficiaries to be invited in the center of attention - and improvise for others to follow. In this particular situation we can also talk about the development of creativity. In some of the dance classes and it also depends on the type of dancing participants expressed their joy through verbal expression. Dancing offered the occasion to improvise, in a way I have already mentioned, but also in a competition when the participants forgot the learned dancing routine so they followed the improvisation of their leader (the young woman who has a Zumba teacher diploma).

The volunteer who participated in the study said: "sometimes I follow their movements". She was the coordinator of the class, so these dancing classes were about empowerment and collaboration. As in other cases it is implied that the beneficiaries like to be the center of attention and dancing is a way of getting it.

As far as communication skills go: dancing offers an occasion to socialize with new people; also, it becomes easy to communicate to people you have never met before, with or without disabilities. This might be associated with the fact that dancing permits the expression of feelings through facial expression and body movement.

At some point in time (not at the beginning but sometimes later) they participated in classes (for about one year and a half) where they learned the basics of dancing, for example the importance of balance and how to practice it.

Ballet lessons offered a model for learning - a sequence which was applied (transferred) to other activities, like making coffee. For some people it initiated a way to learn discipline, for others it just continued what they had already known. Ballet lessons offered occasions to put in effort and test (in a good way) the limits.

Among psychological benefits, one of the most important is relaxation. One mother said "She feels good, she opens up". This also goes to communication skills. The story of dance lessons started a few years ago, and it got to the point where a person with a pronounced disability went home and showed her mother steps she learned in class (and this was a small miracle). She is an introvert, in the words of her mother "you have to meet her four or five times before she just starts to get close to you but when dancing she goes very quickly to you, so I think music and dancing are beneficial for them, so as 
long it makes the closeness between them ... when we went to competitions, there is always and opening festivity, and after that there is dancing, ..., well in dancing they are all together in circles, they turn to each other, they are happy, they laugh, they are open, exuberant, they are more warm to each other even if they have never met before, they talk to each, they ask - who are you, where are you from". Situations where dancing is involved are opposed to situations where each competitor waits for his or her turn but they don't talk to each other. The mutual communication and interaction are possible when dancing is involved. The same mother observed how they give each other support, irrespective of the type of dancing involved: if somebody sits on one side, doesn't dance and looks sad, that person would be invited to dance. They support each other much more than they do it in other types of activities. „It comes naturally to them to dance". This naturalness came as a process - at the beginning they were more shy and withdrawn to themselves but now it comes very easy to them to go and invite somebody to dance. They enjoy any kind of music, from folk music, going to rock and opera, classical music. Of course, each of them has personal preferences.

One observation repeated in stories: the need for routine and repetition. In order to learn the movements, they need to be repeated in the same order for many times. One mother said that her son starts every day with gymnastics, it is compulsory for him to do a few exercises before the day begins. Another mother observed that her son discovered the "joy" of hard work and dedication, "he is very serious, the teacher is proud of him" during ballet lessons.

It is of large consensus among the respondents that dancing is a way of expressing emotions and that they like to be the center of attention. At the first center, beneficiaries danced on national and international stages to express their dancing skills. At the second day center, the occasion to be the center of attention was provided during classes: the young people with DS took turns in showing their classmates moves; the beneficiaries of the third day center participated in dance shows and theater plays by responding to the invitation of the local university and institutions.

In one of the three day centers music therapy was practiced before dance therapy. Dancing and theater activities followed completing the range of benefits. In this case the respondent of the interview was the coordinator of the music and dance therapeutic activities. She stated the difference between therapeutic activities and performance: the dance or music therapeutic activity is about the free expression of self, whilst performance must follow certain steps, schedule, or program. In this context she reminded us (like other respondents) how difficult it is for young people with DS to learn steps and predefined sequences. Of course, the upside of this is the improvement of personal learning skills, communication skills, and patience.

Because of physical limitations and differences beneficiaries often dance in a personal way, following the instructions in a relative way. The upside is that they express their emotions in a personal way and they are creative.

It is a general observation that beneficiaries miss dancing activities if there is a vacation and they participate with enthusiasm in dancing activities. One mother observed the behavior of her son when the activities are on vacation: he delves into a 
fantasy world, he needs to find a refuge. One mother said: "when dancing activities are scheduled everybody is present, nobody is missing". Dancing and movement became a way of life, they exercise and dance at home.

The lack of social programs for dance and movement was very obvious. If the family took upon itself the task to involve the people with DS in activities with music, dancing and movement they had some background with it, and it eased the involvement in the activities offered by the NGOs. Otherwise the beginnings and the involvement are very difficult. Also the learning process is very difficult without any prior exercise or knowledge. It is clear that the state's initiation and involvement in such programs is needed.

In the next table we have a summary of benefits in relationship to a few dimensions for each benefit:

\begin{tabular}{|l|l|}
\hline Benefits of dancing & Dimensions \\
\hline social inclusion & $\begin{array}{l}\text { they meet and interact with other other people, with or } \\
\text { without disabilities; }\end{array}$ \\
\hline increased self esteem & $\begin{array}{l}\text { dance on scenes; } \\
\text { dance in public places; }\end{array}$ \\
\hline improved social skills & $\begin{array}{l}\text { they communicate either verbally or through dancing with } \\
\text { other people }\end{array}$ \\
\hline transferable learning skills & $\begin{array}{l}\text { ballet sequence served as a support to learn how to make } \\
\text { coffee }\end{array}$ \\
\hline relaxation & $\begin{array}{l}\text { visible in the body } \\
\text { attachment to dances speaks about it }\end{array}$ \\
\hline patience & the difficulty of the learning process improved patience \\
\hline music knowledge & listening to all kinds of music genres \\
\hline
\end{tabular}

I think it is important to mention that it was a 'journey' that started with the beneficiaries being shy, withdrawn or scared and it helped them get to a point where they are open to communication, relaxed in social situations and eager to express themselves. As a conclusion, I can say that what we have here is a model of social integration through dancing.

\section{Conclusion}

The present study confirms the results of other studies, and it adds a few more details. Both in the general population and in people with Down's syndrome, dance serves as a way of communicating feelings. In one study (Leseho \& Maxwell, 2010) the authors found a connection with the sacred, and this connection was not present in our 
study. Otherwise, pertaining to self - esteem, creativity, communication skills, learning skills, self - imposed discipline and relaxation the results are the same: dancing has positive effects on each of them.

The respondents in the present study emphasized the special relationship with music. There is a large scale of preferences, the stories contain references to more than ten music genres. This diversity influences the course of dance therapy, especially if the differences are in the interior of one group. In this case the members of the group might negotiate in favor of one or another kind of music, melody, etc. Music a subject briefly analyzed in other studies.

Also, it is clear that dancing activities offer opportunities for social integration, among people with Down's syndrome from different cities for example, and it makes it very easy to socialize with anybody who dances. In our study dancing activities enhanced social skills in multiple ways: some of them were direct, people with DS interacted with volunteers, dance instructors, spectators to their dances. They travelled because of dancing and this is by itself a socializing opportunity.

Limitations and suggestions for further studies go with the methodology. It is a qualitative study and it has certain limitations. Some of the studies in literature are based on standardized questionnaires.

Another limit pertains to the fact that no interviews with people with Down's syndrome were included. For further studies I think that they should be interviewed and I suggest that this should be done in the same way that children would be interviewed. Also I think further exploration of the relationship to music would be more than welcomed.

\section{References}

Albin, C. M. (2016). The Benefits of Movement. Dance/Movement Therapy and Down Syndrome. Journal of Dance Education, 16(2), 58-61 DOI:10.1080/15290824.2015.1061196.

Leseho, J., \& Maxwell, L. R. (2010). Coming Alive: Creative Movement as a Personal Coping Strategy on the Path of Healing and Growth. British Journal of Guidance and Counselling, 38(1), 17-30. DOI: 10.1080/03069880903411301.

Payne, H. (2004). Dance Movement Therapy: Theory and Practice. Brunner: Routledge.

Reindeires, N., Bryden P. J., \& Fletcher P. C. (2015). Dancing with Down's syndrome: a phenomenological case study. Research in Dance Education, 16(3), 291-307. DOI: 10.1080/14647893.2015.1036018.

Silveira de Farias, L. H. \& Teixeira-Machado, L. (2016). Behind the Dance: Educational, Emotional and Social Contexts in Down syndrome. International Journal of Humanities Social Sciences and Education, 3(1), 20-23. 